\title{
Trabalhonecessário
}

Issn: $1808-799 X$

ano 14, número $24-2016$

\section{A CRISE DO HOMEM CONTEMPORÂNEO E O SOCIALISMO, DE KAREL KOSIK}

Sonia Maria Rummert

O ano de 1968 constituiu, em boa parte do mundo ocidental, um paradigma nos processos de luta e resistência contra distintas formas de opressão. Em meio a uma vasta produção intelectual acerca do tema, objeto de debates até hoje, destacam-se escritos relativos à chamada Primavera de Praga, sobre a qual se deteve, por exemplo, o filósofo de origem tcheca Karel Kosik. Foi um de seus escritos sobre os acontecimentos na Tchecoslováquia que deu origem ao primeiro texto seu publicado no Brasil, A crise do homem contemporâneo e o socialismo.

O referido artigo foi publicado, primeiramente, no semanário italiano II Contemporâneo, de 26 de junho de 1968. No mesmo ano, o texto foi traduzido e publicado no Caderno Especial no 3, da Revista Civilização Brasileira, de setembro de 1968, intitulado Tchecoslováquia: Análise dos aspectos políticos, econômicos e culturais da Crise de Agosto. É importante assinalar que a RCB, periódico de importância inversa ao seu curto período de existência, de 1965 a 1968, constituiu espaço fundamental de resistência ao Golpe Civil-Militar de 1964 e de reorganização e revitalização das forças de esquerda que lutavam pela democratização do país.

O livro de Karel Kosik, Dialética do Concreto, originalmente publicado em 1963, chega ao Brasil no ano seguinte, 1969, pela Editora Paz e Terra, do Rio de Janeiro. A obra, traduzida para diversos idiomas como o alemão, o francês, o grego, o inglês, o italiano e o japonês, foi considerada por muitos como uma das mais importantes contribuições filosóficas da década. Devido à 
Issn: $1808-799 X$

ano 14, número 24 - 2016

sua posição e militância política no decorrer da Primavera, Kosik foi duramente perseguido. Para o filósofo Adolfo Sánchez Vázquez,

"Kosik pagou duramente sua contribuição a essa experiência, não só com as medidas de perseguição ditadas contra ele, como, sobretudo, com o silêncio e o isolamento forçados impostos à sua pena e sua palavra, ou seja, seu labor teórico marxista como trabalhador docente e como pesquisador" (Apud. Pompe, Carlos, 2013).

No dia 25 de abril de 1975, a polícia checa invadiu a residência de Kosik, tendo, entre outras coisas, "sequestrando mais de mil páginas inéditas de seus manuscritos filosóficos. Ali estavam rascunhos das obras que dariam continuidade à Dialética do Concreto: uma denominada Da Prática e outra Da Verdade" (Pompe, Idem). Como afirmado em documento da Radio Praga, de 2001,

\footnotetext{
"En 1970, dos años después de la ocupación de la antigua Checoslovaquia por los ejércitos del Pacto de Varsovia, Karel Kosík fue acusado de revisionismo antimarxista por las autoridades comunistas y expulsado de la Universidad. Hasta la "Revolución de Terciopelo", de 1989, prosiguió publicando en la clandestinidad".
}

Vinte anos depois da publicação do Caderno Especial da RCB, mais uma vez o artigo de Kosik recebe destaque no Rio de Janeiro. Desta vez, integrando o primeiro número do Caderno Rioarte, periódico que pretendia dedicar-se à reflexão acerca da filosofia, da literatura, da política, da arte etc. $O$ Caderno foi lançado ao final da gestão do Prefeito Roberto Saturnino, em 1988, quando Miguel Proença, pianista internacionalmente reconhecido, era Secretário Municipal de Cultura e o Presidente do Instituto Municipal de Cultura - Rioarte era Ênio Silveira, diretor da Civilização Brasileira e integrante do Partido Comunista Brasileiro.

Os dois periódicos merecem destaque na história intelectual brasileira e, por isso, julgamos pertinente apresentar aos leitores, em particular os mais jovens, as suas capas originais: 


\section{Trabalhonecessário}

Issn: $1808-799 X$

ano 14, número $24-2016$
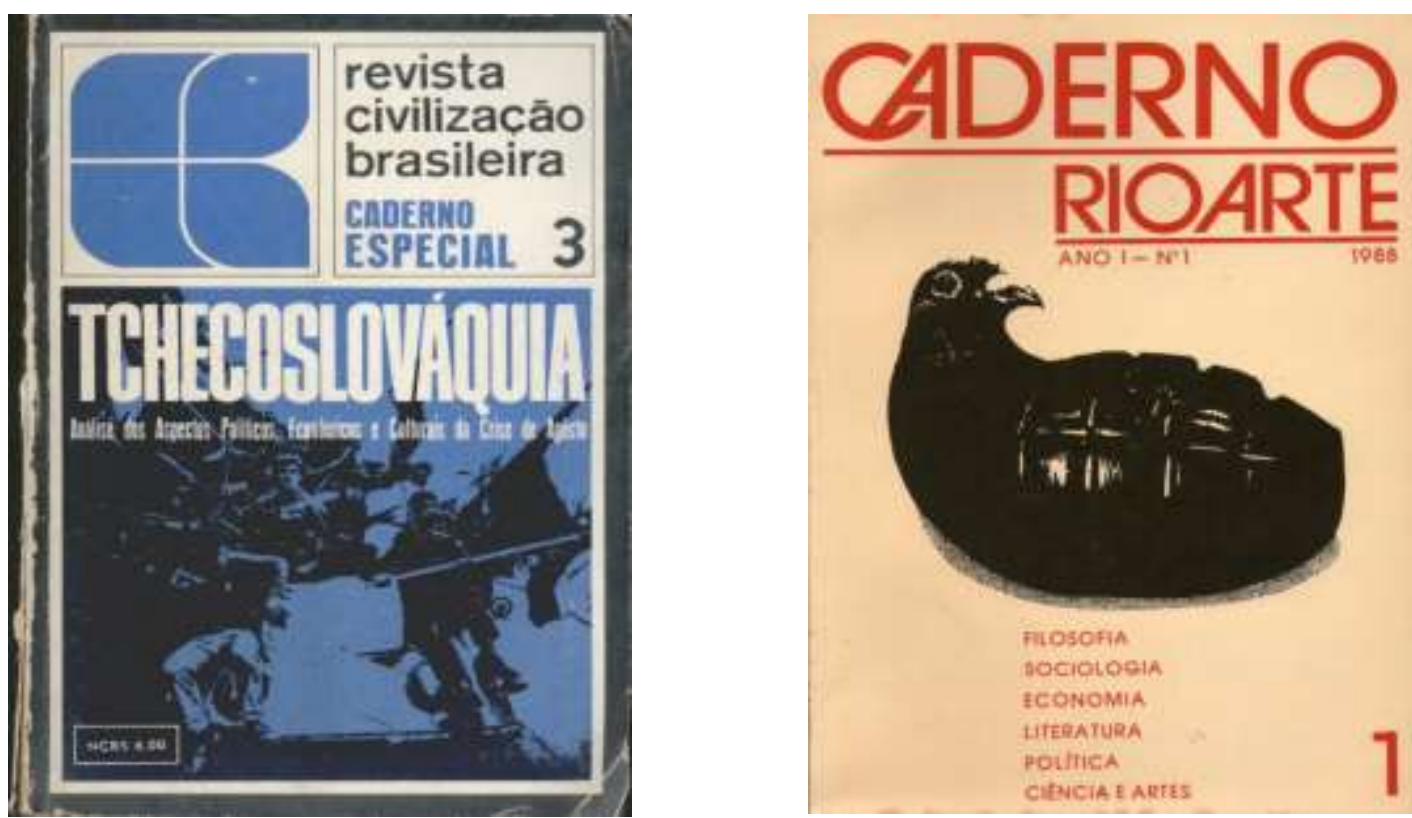

A obra Dialética do Concreto constitui referência essencial na produção crítica do conhecimento acerca das questões educacionais do Brasil até os dias atuais. Entretanto, o artigo de Kosik tem pouco trânsito em nossa área. Daí a opção por apresentá-lo aos leitores da Trabalho Necessário. A escolha, para nós, se torna mais pertinente quando vivenciamos no Brasil um trágico período de retrocesso político em que a incipiente e frágil democracia burguesa aqui instalada sofre vigoroso golpe.

Em momentos históricos como o atual, retomar Kosik é, também, um ato de resistência. É uma fonte de inspiração necessária, o que pode ser facilmente constatado com a leitura. Nela encontraremos, por exemplo, o discípulo Lukács referindo-se, mais uma vez, ao princípio de manipulabilidade geral:

"uma das grandes ilusões do homem moderno, que constitui a particularidade da falsa consciência moderna, é a ideia de que se possa projetar a realidade (o ser) como objeto, como argumento de exploração, como existente subjugável e disponível, e que ao mesmo tempo se possa permanecer de fora deste projeto (grifo no original). 
Issn: $1808-799 X$

ano 14, número $24-2016$

Certamente é essa uma das grandes ilusões que agrega aqueles que urdem e apóiam o golpe que hoje assalta "a nossa pátria mãe tão distraída", da qual nos fala Chico Buarque. Sobre esses, Kosik diria que são expressão de um tipo de política que "desperta nos homens resentimentos, interesses privados, preconceitos, baixos instintos e neles oblitera o sentido da justiça e da verdade; os excita à vulgaridade e à violência".

A nós cabe, como sempre nos coube ao longo da história, o exercício permanente de uma outra política. A que "se preocupa em desenvolver com forças próprias e sustentáculos próprios, aquelas tendências, paixões, capacidades, potências e posibilidades do homem que the possibilitem viver poeticamente e livremente, na terra". Não é outra a tese central que nos move contra o "ideário" da escola sem partido. Como se pode depreender, as reflexões de Kosik parecem, em muitos momentos, inspiradas na realidade brasileira. Por assim entendermos, desejamos que seu artigo seja uma inspiradora leitura.

\section{Referências}

Kosik, Karel. A crise do Homem contemporâneo e o socialismo. Revista Civilização Brasileira. Tchecoslováquia. Análise dos aspectos Políticos, econômicos e culturais da crise de agosto. Caderno Especial 3. . Caderno Rioarte Ano I - № 1, 1988 Rioarte/Fundação

Rio p.215-223.

Kosik, Karel. Dialética do concreto. 2 ed. Rio de Janeiro: Paz e Terra, 1976. Pompe, Carlos. Kosic, um filósofo da ação. Portal Vermelho. 18 de Fevereiro de 2013.2 Disponível em http://www.vermelho.org.br/coluna.php?id_coluna_texto=5121\&id_coluna=2. Acesso agosto de 2016. 
Issn: $1808-799 X$

ano 14, número $24-2016$

Radio

Praga.

Disponível

em

http://www.radio.cz/es/rubrica/personalidades/karel-kosik. Acesso agosto de 2016.

\section{A Crise do Homem \\ Contemporâneo e o Socialismo}

Karel Kosik

Karel Kosik, um dos mais originais pensadores do marxismo contemporâneo, tornou-se conhecido no Brasil pelo seu importantíssimo livro Dialética do Concreto que tivemos a honra de publicar pela Editora Paz e Terra, quando éramos seu diretor, e que constitui leitura indispensável a quem quer que deseja uma atualização filosoficamente dinâmica dos fatos e da criação cultural ou da Estética. Este artigo foi publicado, pela primeira vez, na Revista da Civilização Brasileira, Caderno Especial no 3 de setembro de 1968, dedicado todo ele ao que se passava na Tchecoslováquia. Republicamo-lo pelos motivos com que justificamos, páginas atrás, a oportunidade de uma leitura de Robert Havemam. (Nota de M.F.).

O sentido e o alcance dos atuais acontecimentos da Tchecoslováquia encontram sua melhor caracterização em dois termos hoje cotidianamente presentes em Praga e Bratislava: de um lado crise, de outro socialismo humanístico. Nesses dois termos há muito mais conteúdo do que se possa parecer à primeira vista; vale dizer, eles contêm tanto o estado atual quanto a perspectiva, e constituem, ao mesmo tempo, o ponto de confluência da reflexão e da ação, do pensamento crítico e da política revolucionária. A sociedade tchecoslovaca se encontra em crise e tenta resolver esta crise orientando-se ara um socialismo humanístico. 
ano 14, número $24-2016$

No plano imediato, trata-se certamente da crise de uma determinada camada dominante, de uma determinada forma de relações, de um determinado modelo econômico; e no entanto o caráter desta crise é tal que nela são postos a nu alguns problemas fundamentais da política em geral, da convivência humana em geral. A questão, portanto, é: que é que veio à superfície na crise tchecoslovaca? Qual é o sentido que surge desta crise? Ela aparece como um momento histórico excepcional em que se torna manifesto muito daquilo que em tempos normais fica oculto sob a superfície, ela evidência algo de essencial e fundamental que do contrário dica oculto. A crise tchecoslovaca, portanto, de ser compreendida corretamente: na crise de um país e de uma sociedade, mostra-se e revela-se, de certo modo, a crise do homem moderno e a crise dos fundamentos sobre os quais se apoia a moderna sociedade europeia. Neste sentido os acontecimentos de Praga podem concernir tanto aos homens de Belgrado quando aos de Zurich, Frankfurt ou Paris.

Isto quer dizer, a um exame pouco atento da crise local e nacional da Tchecoslováquia, não escapa o fato de que ela constitui parte integrante da crise europeia e que até esta é ressaltada com insólita plasticidade, evidência e concentração. Assim também delineei a dificuldade da tarefa a hodierna sociedade tchecoslovaca assumiu e cujo sentido ela colocou em termos de socialismo humanístico. Vale dizer que uma solução coerente desta crise pressupões que sejam esclarecidos o sentido do socialismo e da revolução, a missão da política e a inventividade prática de que somos capazes, nos façamos de início a pergunta: Quem é o homem? Que é a realidade, a natureza, a verdade? Que é o tempo, o ser etc.?

Desejaria relembrar, contudo, que os acontecimentos da Tchecoslováquia ainda estão em curso, ainda não atingiram efetivamente o seu momento final e que o resultado do process 0 liberatório iniciado em janeiro de 1968 ainda não está garantido. Se, porém, falei dos acontecimentos da 


\section{Trabalhonecessário}

Issn: $1808-799 X$

ano 14, número $24-2016$

Tchecoslováquia como de um raro instante histórico em que a verdade é desvendada, em que surge na superfície tudo quanto existe de oculto e escondido, tudo quanto é presente de modo latente na realidade europeia do século $X$, devo também falar segundo elemento de significação desta fase; 0 atual momento da Tchecoslováquia se revela momento histórico porque 0 pensamento crítico, os grupos individuais isolados e as forças políticas se encontram diante de possibilidades abertas e têm ocasião de influenciar e plantar o curso dos acontecimentos que provavelmente estabilizarão o caráter das relações e instituições em que os habitantes do nosso país viverão e trabalharão durante decênios. Assim, à teoria e ao pensamento crítico se abriu a rara perspectiva de influir, em certa medida, sobre o curso dos acontecimentos práticos; e de realizar, pelo menos momentaneamente, aquilo que em termos normais permanece como um simples postulado ou um simples desejo: a unidade de teoria e práxis, a unidade de pensamento e ação.

O sistema burocrático que entrou em crise na Tchecoslováquia, e que já agora é substituído por um sistema de democracia socialista, tem que comum, com a aludia crise do homem moderno e com a crise dos fundamentos da sociedade europeia, muitos mais do que possa parecer à primeira vista. Determinadas particularidades históricas deste sistema - que sem dúvidas são importantes e que nas condições reais dos respectivos países se revestem de grande relevo - não devem, porém, esconder a sua origem comum, a sua base comum através de cuja mediação ele é intimamente apresentado com os fatos essenciais do mundo capitalista ocidental. O stalinismo, como sistema burocrático e policialesco de domínio absoluto, funda-se sob a ideia da manipulação geral de homens e coisas, do homem e da natureza, das ideias e dos sentimentos, dos vivos e dos mortos. Base e ponto de partida latentes neste sistema é uma certa - e em grande parte obscura - concepção do homem e do mundo, das coisas e da realidade, da história e da natureza, da verdade e do tempo. 
Issn: $1808-799 X$

ano 14, número $24-2016$

Quando este sistema entrou em crise na Tchecoslováquia, não só certos métodos e formas de domínio absoluto assumiram caráter problemático; também começou a vacilar toso o completo de ideias sobre o homem e a história, sobre a verdade e a natureza; Em outras palavras: os acontecimentos tchecoslovacos, não constituem uma das habituais crises políticas, uma das habituais crises econômicas; são também uma crise dos fundamentos de que derivam as ideias atuais sobre a realidade como sistema manipulabilidade geral.

O socialismo humanístico por cuja existência ou não existência hoje se luta na Tchecoslováquia é uma alternativa revolucionária, humanística e liberatória, para a manipulabilidade geral. E é esta a razão pela qual é claro que, nos acontecimentos da Tchecoslováquia, se trata do socialismo e não, em caso algum de forma alguma, de um regresso do capitalismo, pois este socialismo humanístico é a negação tanto do capitalismo como do stalinismo. Se o experimento tchecoslovaco for bem-sucedido - e seu sucesso depende disto, que ele seja realizado coerentemente e não desça a compromissos com soluções pela metade - nós nos encontraremos diante da prova prática de que o sistema da manipulação geral poder ser superado, em ambas as formas históricas hoje dominantes; tanto na do stalinismo burocrático quando na do capitalismo democrático.

O modo antidemocrático, burocrático, grosseiro e policialesco com que se pratica e realiza, no stalinismo, o sistema de manipulabilidade geral não nos deve fazer esquecer que este mesmo sistema é praticado e realizado também de outro modo, formalmente democrático, requintado, muito menos vistoso e conturbante. O sistema da manipulabilidade geral, característica fundamental do século $X X$, é desenvolvido e aperfeiçoamento do sistema de venalidade geral, típico do século XIX. Neste sentido o nosso sistema é um prosseguimento do século passado, do momento em que, não obstante tentativas e eventos revolucionários significativos e historicamente importantes, 
Issn: $1808-799 X$

ano 14, número $24-2016$

não foram superados os fundamentos de que derivam tanto o sistema de venalidade, corrupção, utilitarismo e alienação geral, analisado, por Marx, quanto o sistema de manipulação geral e da manipulabilidade geral determina de modo decisivo a configuração do nosso tempo. Estes fundamento e origens são encobertos pelas mais diversas ideologias e pelas diversas formas de falsa consciência, de tal modo que elas de um lado se contrapõem entre si como de todo hostis, excluindo aquelas manipulações que, a despeito de todas as diversidades, têm muito em comum; de outro lado encobrem o caráter daquela subversão revolucionária e radical que pode ser e é um real alternativa histórica ao atual sistema de manipulação geral, em todas as suas formas e configurações históricas.

Não digo que entre aquilo que na Tchecoslováquia se chama stalinismo ou stalinismo iluminado e reformulado, e aquilo que no Ocidente se define como sociedade de consumo, não existem diferenças essências e que os dois fenômenos não pertençam a formações socioeconômicas completamente distintas. Pergunto-me, porém, porque em ambos os casos a falsa consciência e a manipulação do homem têm uma função tão essencial; e chego à conclusão de que a causa suficiente e a origem de ambos os fenômenos é uma oculta e obscura concepção comum a ambos, do homem e da realidade. Com o termo "concepção" não entendo aqui a consciência teorética, mas ao invés, um real e factual projeto de homem e do ser, fixado nas atitudes, nas relações intersubjetivas, no relacionamento do homem com as coisas e a natureza, de maneira de revelar a verdade; fato que se reproduz na vida cotidiana de milhões de homens e sobre cuja base estes formam as representações de si mesmos e do mundo. Característica do sistema da manipulabilidade geral não é só o predomínio da falsa consciência nas representações que o homem se faz, de si e do mundo, mas sobretudo e especialmente a decadência e o deperecimento da capacidade de distinguir entre verdade e mentira justamente 


\section{Trabalhonecessário}

Issn: $1808-799 X$

ano 14, número $24-2016$

com o desinteresse da massa ou a obtusão do interesse pela distinção entre verdade e falsidade, entre bem e mal.

Pendant natural da conhecida ideia de que algumas épocas têm uma atitude hostil nos confrontos da arte, pode ser considerada a opinião de que determinadas sociedades podem avançar mesmo sem a verdade, que dela não tenham necessidade para a própria existência. A primeira ideia não é contraditada por centenas de obras de arte, mas por elas é confirma: porque exatamente a existência de tais obras de arte demonstra que a produção artística e as duas criações não conseguem mudar a impoética e antiartística base da época e a atmosfera prosaica da vida cotidiana. E, igualmente, a conquista metodicamente garantida de conhecimentos e colossal acúmulo de noção não abalam a segunda opinião, mas a confirmam: porque documentam importância da ciência moderna diante do fato de que determinadas sociedades cuidam da ciência e utilizam os conhecimentos, mas ao mesmo tempo produzem, em escala de massa e cotidianamente, a mistificação e a falsa consciência como condição de vida indispensável à sua existência.

No sistema de manipulabilidade geral o homem perde a capacidade e a necessidade de distinguir e, por conseguinte, também a capacidade e a necessidade de fazer distinção entre verdade e falsidade, entre bem e mal: trata-se de um sistema de indiferença e equivalência, onde são misturados a verdade com a falsidade, o bem com o mal. A equivalência elevada à categoria dominante e estrutural da realidade significa uma parificação de verdade e falsidade, bem e mal, nobreza e baixeza, e, em consequência, um nivelamento e uma desvalorização gerais: tudo é do mesmo modo válido e não-válido, porque tudo perde seu sentido íntimo. A falsa consciência no sistema de manipulabilidade geral não é criada, portanto, através da falsidade e da mentira (que são distintas da verdade), mas através da justaposição, da desagregação e da indiferenciada confusão do verdadeiro e não-verdadeiro, de bem e mal. Neste sistema, a equivalência aparece de um lado como atmosfera cotidiana 


\section{Trabalhonecessário}

Issn: $1808-799 X$

ano 14, número $24-2016$

em que vivem e agem os homens, transformados em massa, do outro lado como incapacidade e desinteresse ou interesse enfraquecido em distinguir: a equivalência (indiferença) assemelha-se a uma obtusão, enevoamento, acegamento da sensibilidade, do sentimento e do intelecto.

O sistema da manipulabilidade geral se apoia sobre um projeto técnico da realidade: o intelecto técnico projeta a realidade como objeto de dominação, calculabilidade, disponibilidade e perfectibilidade. Para se tornar parte integrante do sistema, o homem, as coisas, a natureza, as ideias, a sensibilidade, devem primeiro ser submetidos a uma inversão e mudança de fundo, ligada à época, em que o ser se reduz ao existente, o mundo à res extensa, a natureza aos objeto da exploração ou a $\mathrm{m}$ conjunto de leis físicomatemáticas, o homem a um sujeito imputado a um determinado objetivo: e, ao mesmo tempo, a verdade se reduz a justeza ou utilidade, a dialética a um simples método ou conjunto de regras e ao fundo a uma operação totalmente técnica. Esta redução de fundo e ligação à época se torna o pressuposto da equivalência (indiferença) no sistema da manipulabilidade geral.

O homem é pintado a este sistema como unidade manipulável: uma das grandes ilusões do homem moderno, que constitui a particularidade da falsa consciência moderna, é a ideia de que se possa projetar a realidade (o ser) como objeto, como argumento de exploração, como existente subjugável e disponível, e que ao mesmo tempo se possa permanecer de fora desse projeto. $\mathrm{Na}$ realidade, o homem, por causa da índole relativa que o sistema recebe em consequência deste projeto, é ele próprio inserido no sistema, projetado como parte integrante dele, e é submetido à sua lógica. Quando, pois, o homem moderno sente o carácter problemático de sua posição e o traduz para a consciência com termos como frustação, absurdidade, contrassenso, alienação, e procura uma explicação sociológica, psicológica ou histórica destes fenômenos, ele se ocupa simplesmente das consequências, suas pesquisas não vão ao fundo, embora revelem coisas importantes e apreciáveis. 


\section{Trabalhonecessário}

Issn: $1808-799 X$

ano 14, número $24-2016$

O intelecto técnico projeta a realidade não apenas como objeto de dominação, utilitarismo, calculabilidade e disponibilidade, como campo daquilo que está diante de nós e é fundamentalmente previsível, manobrável e controlável, mas também como perfectibilidade e maligna infinidade. $\mathrm{Na}$ perspectiva do intelecto técnico, tudo é transitório e provisório porque tudo quanto existe é simplesmente um imperfeito degrau que procede aquilo que será, e assim ao infinito. Tudo quanto existe, se olha para a frente, no infinito processo de aperfeiçoamento e melhoramento, é relativo. Do ponto de vista de 1864 o hoje é não só algo imperfeito, mas até um simples ponto de trespasse. A perfectibilidade absoluta como maligna infinidade dissolve tudo em um infinito processo de aperfeiçoamento, retira de todo - às coisas, aos homens, às ideias - o sentido próprio e o valor intrínseco, e a tudo dá sentido e valor no quadro e sob o aspecto deste processo infinito: todas as coisas têm sentido e valor só enquanto ponto de transição do processo.

Mas, se nesta maligna infinidade tudo perde o seu sentido intrínseco, as coisas são desreificadas e os homens reificados: se tudo é equivalente, porque tudo é permutável e manipulável, a última consequência e o desfecho lógico da redução fundamental de que falamos - sobre a qual se apoia o sistema de manipulabilidade geral - acaba sendo o niilismo.

Talvez seja necessário ressaltar que eu uso, aqui, a expressão "intelecto técnico" como termo filosófico e não tenho a menor intenção de diminuir a importância da técnica e do pensamento técnico. A humanidade moderna não pode avançar sem a técnica, e o processo técnico é um dos pressupostos da libertação do homem. E, todavia, a essência da técnica é desenvolvida por dois preconceitos nos seus confrontos hoje dominantes: a fé acrítica na onipotência da técnica e do processo técnico, os quais em si e por si devem trazer liberdade à humanidade; o despique romântico nos confrontos da técnica, e o medo de que ela escravize o homem. A essência da técnica não se baseia nas máquinas e nos instrumentos automáticos, mas no intelecto técnico que projeta 


\section{Trabalhonecessário}

Issn: $1808-799 X$

ano 14, número $24-2016$

a realidade como sistema de disponibilidade, objetivação e perfectibilidade. E por mais que possa parecer extraordinário a quem julgue as coisas vulgarmente, sobre a essência da técnica dizem-nos muito mais a "maligna infinidade" de Hegel, a "perfectibilidade"” de Condorcet, a doutrina kantiana sobre os fins e os meios, a análise do capital feita por Marx - muito mais do que o mais acurado estudo da tecnologia e das pesquisas e descobertas científicas. O homem não está ameaçado pelas máquinas. A escravizante soberania da técnica sobre o homem não significa que existe uma insurreição das máquinas e dos instrumentos automáticos contra o homem. Com esta terminologia técnica os homens se tornas conscientes, mas só obscuramente, do perigo que os ameaça: isto é, o intelecto técnico é identificado com o intelecto geral; o intelecto técnico domina sobre a realidade de tal modo que acaba contrapondo, a si e ao homem como não-intelecto, tudo quanto não é técnico, disponível, manipulável e calculável.

Neste contexto é claro que a razão dialética, como oposto do intelecto técnico, não significa contestação da técnica e destruição do intelecto técnico; significa simplesmente afirmação dos limites dentro dos quais a técnica e o intelecto são válidos. A razão dialética é sobretudo esvaecimento da mistificação que idêntica o intelecto técnico com o intelecto em geral, e que realça como absolutas as exigências do intelecto técnico. Neste sentido a razão dialética se apresenta antes de tudo como pensamento crítico que empreende a destruição das mistificações e das pseudoconcretividades, e indica as realidades como elas são, dizer, reconfere a todas as coisas existentes o seu próprio sentido intrínseco. A dialética assim entendida obviamente não é um simples método e muito menos um conjunto de regras; não é uma simples totalização, tampouco se limita à realidade histórico-social: ao invés, nasce no ambiente do pensamento crítico desmistificante e, portanto, está mais próxima da sabedoria do que presteza já aplicação de certas regras 


\section{Trabalhonecessário}

Issn: $1808-799 X$

ano 14, número $24-2016$

de pensamento, e, ao mesmo tempo, está intimamente ligada à problemática do ser, da verdade e do tempo.

$\mathrm{Na}$ Tchecoslováquia, juntamente com a derrocada de uma determinada camada dominante e de uma determinada política, ocorreu a crise do sistema da manipulabilidade geral e se desvendam os fundamentos invisíveis, escondidos, sobre os quais ele se apoia. Compreende-se agora por que o socialismo humanístico não pode ser uma simples operação política ou econômica, sabem que no contexto imediato se trate principalmente de dar uma solução, a deformações políticas e a dificuldade econômicas. Este socialismo humanístico aparece como alternativa revolucionária, e humanística e liberatória, em relação a toda e qualquer subespécie de sistema da manipulabilidade geral e, portanto, se apoia sobre fundamentos totalmente outros e parte de toda uma outra concepção do homem, do ser, da natureza, da verdade e da história.

$\mathrm{Na}$ crise tchecoslovaca estuda-se tudo de novo, praticamente e teoricamente; questões claras ou de já muito resolvidas perdem a sua objetividade e se demonstram problemáticas, isto é, demonstram-se problemas de vida tão importante que devem ser continuadamente repensados e reestudados a fundo. Entre estas questões, inclui-se até o conceito de socialismo. É talvez surpreendente que na crise tchecoslovaca - depois de todas as experiências feitas - aflore a pergunta: Que é propriamente o socialismo? Esta pergunta não visa apenas a ilibar o socialismo de todas as crueldades e monstruosidades que se cometeram em seu nome, mas também a procurar, de novo, o sentido do socialismo. Acontece que os objetivos práticos e as dificuldades, bem como a simples adesão a definições ou a enumerações de características, obnubilaram o sentido histórico do socialismo, de tal modo que o pragmatismos prático e teórico, e o utilitarismo encobriram e empurraram para o fundo o sentido liberatório do socialismo enquanto alternativa revolucionária e humanística em relação à opressão, miséria, 


\section{Trabalhonecessário}

Issn: $1808-799 X$

ano 14, número $24-2016$

exploração, injustiça, mentira e bárbarie; em relação à guerra, à humilhação do homem e à opressão da sua dignidade, à iliberdade, à equivalência etc. Em todas as etapas de seu desenvolvimento, em todas as suas expressões e em todas as suas formas históricas, sempre o socialismo deve ser entendido e definido em relação a estre sentido libertário. Assim a dialética, o caráter crítico e revolucionário, e o humanismo se tornas o verdadeiro e próprio conteúdo intrínseco do socialismo, porque cada degrau, cada ação real, cada forma historicamente realizada é julgada com olhar volvido para este intrínseco. 0 que nos dá ainda a possibilidade de distinguir e cada ação real, em cada forma e cada etapa do socialismo historicamente realizada, aquilo que pertence ao socialismo, isto é, que lhe é próprio, daquilo que, ao invés, apenas e faz passar por socialismo, que não the pertence, e é simplesmente um ser parasita histórico ou uma deformação sua.

Os acontecimentos tchecoslovacos podem induzir a um certo equívoco, se não são claros, para nós, o sentido e o conteúdo das definições que se dão aos acontecimentos. Na Tchecoslováquia o processo atual é definido como democratização, eliminação das injustiças e deformações, reabilitação etc. Desta terminologia poderia derivar a impressão que se trata de acontecimentos cristalizados no passado, cuja tarefa é remediar, melhorar, ajustar o passado; em segundo lugar, que a democratização e a democracia atinjam ao socialismo como algo de externo e suplementar que the é enxertado como corpo estranho. Desejaria, pois, ressaltar que, nos acontecimentos tchecoslováquios, se trata de uma complicada síntese de retorno ao passo e, a o mesmo tempo, da criação de algo de novo e futuro; e isto quando se torna cada vez mais claro que de há muito tempo nem tudo quanto aconteceu neste país, de 1945 até hoje, foi uma etapa necessária e inevitável no caminho do socialismo; certas etapas deste desenvolvimento foram etapas erradas, muitos atos foram erros históricos demonstráveis. A Tchecoslováquia hodierna distingue no seu passado imediato e se reata aos momentos que são incontestavelmente 


\section{Trabalhonecessário}

Issn: $1808-799 X$

ano 14, número $24-2016$

revolucionários e socialistas enquanto rejeita abertamente tudo quanto foi erros e deformação.

É evidente que a socialização dos meios de produção e o domínio da classe operária constituem conquistas revolucionárias às quais a Tchecoslováquia socialista não renuncia, que são e permanecem os pressupostos do hodierno processo revolucionário. Ou melhor: apresentam-se demonstradamente como a primeira e irrenunciável etapa da revolução à qual se segue uma etapa ulterior, que é a vivida nestes dias pela Tchecoslováquia, e cujo sentido não está apenas na eliminação das deformações do passado e na substituição da ditadura burocrática por uma democracia socialista, mas também em um desdobramento do socialismo em harmonia com o seu intrínseco sentido humanístico e liberatório.

Os atuais acontecimentos da Tchecoslováquia - pressupondo-se que 0 experimento tenha bom êxito - deveriam demonstrar que o socialismo e a democracia estão intimamente unidos. Aquilo que é definido como democratização, e que na sequencia histórica é realizado só nesta etapa, pertence à essência intima do socialismo e não só porque reata a tudo quanto de válido e de progressivo as épocas precedentes trouxeram contido (e, portanto, também à época da democracia), mas ainda porque no socialismo a classe operária pode ter uma função política e dirigente só quando existem liberdade de imprensa, liberdade de reunião e de associação. Exatamente a experiência tchecoslovaca mostrou que sem esta liberdade os operários se transformam numa massa manipulável, enquanto a função política é assumida e usurpada pela burocracia.

Entre os caracteres fundamentais do hodierno renascimento da Tchecoslováquia, podemos considerar o fato de que este processo se realiza na aliança revolucionária dos operários e dos intelectuais, onde cada categoria trás os seus traços essenciais peculiares e alcança, depois, uma influência recíproca e permutável. Esta aliança se funda sobre a consciência de que os 


\section{Trabalhonecessário}

Issn: $1808-799 X$

ano 14, número $24-2016$

intelectuais revolucionários e socialistas podem certamente dar início aos acontecimentos; mas sozinhos - sem o apoio e a aliança do povo, em particular da classe operária - não estão em condições de transformar estes acontecimentos em uma operação de toda sociedade, capaz de mudar a estrutura geral. Esta aliança se funda, além disto, na consciência de que a classe operária tem um interesse vital na liberdade e na verdade das informações e das expressões, na destruição das mistificações e da falsa consciência. Cumpre dizer abertamente que esta aliança entre operários e intelectuais foi criada com dificuldade, em um diálogo que superou desconfianças e preconceitos recíprocos, na crítica recíproca, mas também no conhecimento recíproco e pessoal durante as assembleias comuns de intelectuais e operários, realizadas seja nas fábricas, seja nas redações ou universidades. Uma das mais características e originais manifestações desta aliança são as comissões operárias para a defesa da liberdade de imprensa e de informações surgidas espontaneamente nas fábricas e nos locais de trabalho, e cujos membros declaram estar prontos a tomar posição pública, no caso de quem quer que seja tentar desrespeitar a liberdade de informação.

O resultado do atual processo de renascimento na Tchecoslováquia deverá ser a instituição, apoiada nas leis da Constituição, da democracia socialista como ordenamento político que se funda na socialização dos meios de produção e na qual o pode soberano, única fonte de poder, administra a coisa pública de modo a que os trabalhadores sejam não apenas proprietários coletivos, mas também administradores e coparticipes das empresas estatais e que cada cidadão seja jurídica e efetivamente um sujeito inalienável da ida política, dos direitos e deveres políticos. O fundamento da democracia socialista não são as massas anônimas manipuladas e guiadas por um incontrolável grupo dominante (a burocracia política) mas os cidadãos socialistas livres e iguais, na qualidade se sujeitos da vida política. Durante os acontecimentos atuais vão nascendo as células germinais que podem ser 


\section{Trabalhonecessário}

Issn: $1808-799 X$

ano 14, número $24-2016$

consideradas como fundamentos orgânicos e colunas de sustentação da democracia socialista.

A elas pertencem: 1) a Frente Nacional, aliança político-social de operários, camponeses, intelectuais, jovens e empregados, aliança dinâmica que existe no diálogo político recíproco e compreende a possibilidade de uma oposição, bem como de formulação de alternativas numa base socialista; 2) a democracia política com liberdade de imprensa, de expressão, de reunião e de associação, com uma pluralidade política baseada na Frente Nacional; 3) os conselhos operários ou conselhos de produtores, como instituições autônomas dos trabalhadores, que não apenas proprietários coletivos mas também administradores da propriedade nacional (socializada). Neste sentido consideramos a democracia socialista tchecoslovaca como uma democracia integral, assim como somos de opinião que ela só pode funcionar como democracia real com a colaboração e a conexão destes três elementos fundamentais. Se um deles vier a enfraquecer-se, ou a faltar, esta democracia não poderá deixar de degenerar ou de se transformar numa simples democracia formal.

Os atuais acontecimentos na Tchecoslováquia colocaram a política no centro da atenção pública, dela fizeram uma atividade de todos, mas também indicaram os seus problemas. O elemento natural da política é o poder: todavia, depende da essência da política o objetivo para que o poder existente é utilizado para que coisa ele serve. A política não é simplesmente uma reação a situações já criadas e definidas, não é apenas o dispor das forças existentes. Ela não se apoia apenas nas formas sócias, nas camadas e nas classes, mas também nas paixões, na razão e nos sentimentos do homem.

Cada política faz nascer e cria novas forças; porém depende da essência da política as forças que ela suscita e desperta no homem, as forças que neles libera, oprime e adormece. No mundo hodierno a política é parte integrante da educação, porque na vida política são despertadas desenvolvidas 


\section{Trabalhonecessário}

Issn: $1808-799 X$

ano 14, número $24-2016$

estas ou aquelas potencialidades e possibilidades do homem, porque nela adquirem relevo estes ou aqueles modelos de comportamento, de ação, de caráter. Depende do tipo de política, se ela, lutando pelo poder ou pela sua conservação, e aplicando-se e exercitando-o, desperta nos homens ressentimentos, interesses privados, preconceitos, baixos instintos e nele oblitera o sentido da justiça e da verdade, os excita à vulgaridade e à violência; ou então, ao contrário, se preocupa em desenvolver, como forças próprias e sustentáculos próprios, aquelas tendências, paixões, capacidades, potências e possibilidades do homem que the possibilitem viver poeticamente e livremente, na terra. A política é sempre também direção de homens, mas depende da sua essência quem ela deseja dirigir e quem efetivamente dirige: se massas anônimas, ou então homens que desejam ser cidadãos livres e responsáveis.

Os atuais acontecimentos na Tchecoslováquia representam, portanto, também uma contribuição à discussão sobre a essência e a missão da política e sobre suas possibilidades no mundo de hoje. (traduzido de II Contemporâneo, de 26-6-68, por Célia Neves.) 